\title{
高速炉蒸気発生器における伝熱管破損時ウェステージ環境評価モデルの構築*
}

\author{
内堀 昭寛 ${ }^{* 1}$, 大島 宏之 ${ }^{* 1}$
}

\section{Development of Evaluation Model for Wastage Environment under Tube Failure Accident in Steam Generator of Sodium-Cooled Fast Reactor}

\author{
Akihiro UCHIBORI ${ }^{* 1}$ and Hiroyuki OHSHIMA \\ ${ }^{* 1}$ Japan Atomic Energy Agency \\ 4002 Narita, Oarai, Ibaraki, 311-1393 Japan
}

\begin{abstract}
In order to establish a safety evaluation method of a steam generator in sodium-cooled fast reactors, a computer program called SERAPHIM to calculate compressible multicomponent multiphase flow with sodium-water chemical reaction under tube failure accident has been developed. In this study, a numerical model for liquid droplet entrainment from an interface of the gaseous jet and its transport was newly constructed to evaluate the environment of the liquid droplet impingement erosion. Applicability of the SERAPHIM program which incorporates the droplet entrainment / transport model was investigated through the analysis of vertical discharging of water vapor in the liquid sodium pool. The numerical analysis reproduced the underexpansion of the vapor jet, which appears under the actual condition of the tube failure accident. The calculated peak temperature agreed with the experimental results well. Also, appearance of the dispersed phase of droplets in the reacting jet and movement with the supersonic gaseous flow were calculated successfully.
\end{abstract}

Key Words : Sodium-Cooled Fast Reactor, Steam Generator, Sodium-Water Reaction, Multi-Phase Flow, Liquid Droplet, Numerical Simulation

\section{1. 緒言}

ナトリウム $(\mathrm{Na})$ 冷却高速炉の蒸気発生器（SG）において伝熱管壁に貫通破損孔が生じると，高圧の水または 水蒸気が $\mathrm{Na}$ 中一噴出し, $\mathrm{Na}$ と水の化学反応を伴う高速・高温・腐食性ジェットが形成される. 隣接する伝熱管 にこの反応ジェットが衝突すると，管壁の損耗（ウェステージ）や高温化に伴う強度低下を引き起こし，それら が進行すると隣接伝熱管が二次的な破損に至る (破損伝播).SG の設計及び安全評価では, このような破損伝播 の発生する可能性を評価することが重要な課題となっている．著者らは，隣接伝熱管周りに形成されるウェステ ージ環境を評価することを目的として, Na一水化学反応を伴う圧縮性多成分多相流数值解析コード SERAPHIM の開発を進めている. 図 1 に, SERAPHIM で評価する事象を示す。これまでの研究では, 圧縮性多成分多相流や $\mathrm{Na}$ 一水化学反応に対する解析モデルを開発し，それらの妥当性を示した ${ }^{(1)}$.

隣接伝熱管のウェステージ現象を引き起こす主たる要因の一つとして, 反応ジェットの界面で巻き込まれた液 滴による液滴衝突エロージョンがある. エロージョン速度を評価するためには, SERAPHIMにより液滴の挙動を 解析し, 液滴の存在量や隣接伝熱管への衝突速度を得ることが必要である. そこで本研究では, ウェステージ環 境評価モデルの一つとして, 液滴のエントレインメント及び輸送現象に対する解析モデルを新たに構築し, SERAPHIM 一組み込んだ．本モデルの基本検証を目的に，実機条件における Na 中水蒸気噴出現象の数值解析を 実施した.

\footnotetext{
* 原稿受付 2012 年 8 月 29 日

*1 正員, (独) 日本原子力研究開発機構（广311-1393 茨城県東茨城郡大洗町成田町 4002）

E-mail: uchibori.akihiro@jaea.go.jp
} 


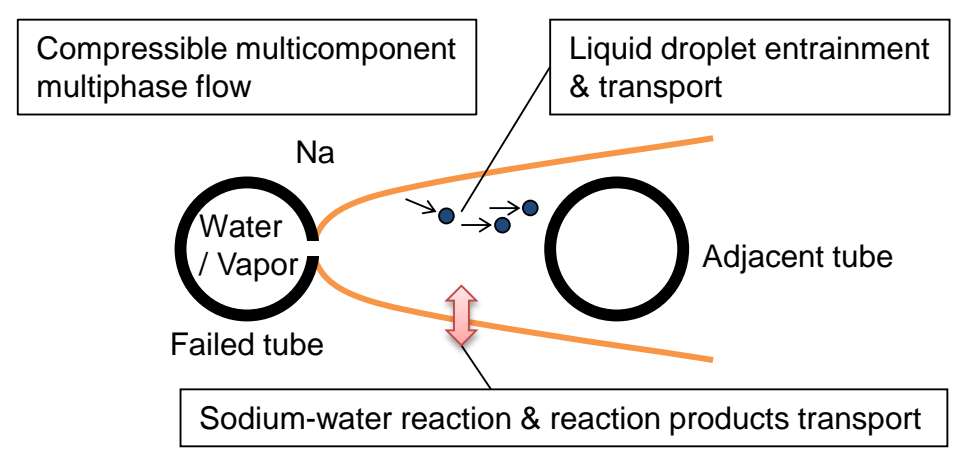

Fig.1 Phenomena to be evaluated by SERAPHIM code

\section{2. 数值解析手法}

\section{$2 \cdot 1$ 圧縮性多成分多相流解析モデル}

SERAPHIM では多流体モデルを採用し，伝熱管から噴出した水蒸気や反応生成物を含む多成分気相と，液体 $\mathrm{Na}$ あるいは水からなる多相流を計算することが可能となっている.気相中の成分種の輸送は移流拡散方程式によ り計算する．基礎方程式の解法には，圧縮性多相流に適用できるよう修正を施した HSMAC 法を用いる．本解法 では，各相体積率の総和が 1 になることを制約条件とするとともに密度変化（圧縮性）を考慮した圧力修正式を 用いており，これが従来の HSMAC 法と異なる点である.

\section{$2 \cdot 2$ 化学反応モデル}

水蒸気と液体 $\mathrm{Na}$ の接触界面では次の化学反応が発生する.

$$
\mathrm{Na}+\mathrm{H}_{2} \mathrm{O} \rightarrow \mathrm{NaOH}+1 / 2 \mathrm{H}_{2}
$$

（1）式における物質の生成・消滅速度については, 化学反応の進行が接触界面への水蒸気輸送速度に律速される と仮定した（反応速度無限大）表面反応モデルにより評価する．本モデルでは，熱伝達と物質伝達のアナロジに 基づいて気液界面への気相の輸送速度を求める，反応生成物は気相中へ移行することを仮定しており，気相は多 成分となることを考慮している.

\section{$2 \cdot 3$ 液滴エントレインメント・輸送モデル}

本研究で新たに構築した液滴エントレインメント・輸送モデルの概要を以下に述べる. 液滴は分散相として考 慮することとし, 液滴に対応する質量・運動量・エネルギー保存式を SERAPHIM 一組み込んだ. これらの保存

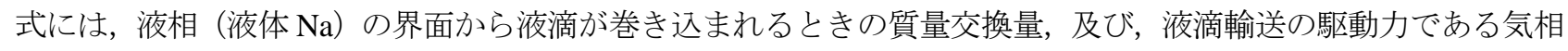
一液滴間の抗力を表す項が含まれている. 質量交換量（液滴エントレインメント量）を表す項については，以下 に示寸 Ricou-Spalding の式(2)から計算した.

$$
\dot{m}_{e}=E_{0}\left(\rho_{g} \rho_{l}\right)^{1 / 2}\left|\mathbf{u}_{g}-\mathbf{u}_{l}\right|
$$

ここで, $\dot{m}_{e}$ は単位時間, 単位面積当たりの液滴エントレインメント量, $E_{0}$ はエントレインメント係数, $\rho$ は密度, $\mathbf{u}$ は速度, 下添字の $g$ は気相, $l$ は液相である. Epstein $ら^{(3)}$ は, Na 中水蒸気噴出現象に対する 1 次元モデルを用 いた評価から $E_{0}$ の值として 0.08 を提案しており，本モデルでも同様とした．気相一液滴間の抗力を計算するた めに必要な抗力係数 $C_{D}$ については, 超音速気流中の固体粒子に対する以下のモデル(4)を適用して評価した.

$$
C_{D}=\frac{24}{\operatorname{Re}_{d}}\left(1+0.15 \operatorname{Re}_{d}^{0.687}\right)\left[1+\exp \left(-\frac{0.427}{M_{r}^{4.63}}-\frac{3}{\operatorname{Re}_{d}^{0.88}}\right)\right], \operatorname{Re}_{d}=\frac{\left|\mathbf{u}_{g}-\mathbf{u}_{d}\right| D \rho_{g}}{\mu_{g}}, M_{r}=\frac{\left|\mathbf{u}_{g}-\mathbf{u}_{d}\right|}{\sqrt{\gamma R T_{g}}}
$$


ここで, $\operatorname{Re}_{d}$ は液滴レイノルズ数, $M_{r}$ は相対マッ八数, $D$ は液滴径, $\mu$ は粘性係数, $\gamma$ は比熱比, $R$ は一般気体定 数, $T$ は絶対温度である. 液滴径 $D$ についてはいくつかの評価方法があるが, 本報では不足膨張噴流中の Sauter 平均液滴径を表す次の相関式(5)を用いた。

$$
\frac{\mathrm{SMD}}{d_{0}}=0.39\left(\frac{\sigma}{u_{0}^{2} \rho_{0} d_{0}}\right)^{0.4}
$$

ここで, SMD は Sauter 平均径, $\sigma$ は表面張力, $d_{0}, u_{0}, \rho_{0}$ は気体噴流が不足膨張した後の噴流径, 流速, 密度で ある. なお，液滴相に対しても前節に示した表面反応モデルにより水蒸気との化学反応を考慮した.

\section{3. 数值解析}

\section{$3 \cdot 1$ 解析体系及び条件}

図 2 に示寸 1 辺 $0.4 \mathrm{~m}$ の 3 次元矩形領域を基本検証解析の対象とした. 解析領域は最初液体 $\mathrm{Na}$ で満たされた状 態にあり，底面中央に設けた口径 $2 \mathrm{~mm}$ の円孔に相当する噴出口より水蒸気が鉛直上向きに噴出する. 温度と圧 力の条件については, 実機と同等に $\mathrm{Na}$ の初期温度は $520^{\circ} \mathrm{C}, \mathrm{Na}$ の圧力は $0.2 \mathrm{MPa}$, 水蒸気温度は $520^{\circ} \mathrm{C}$, 水蒸気 圧力は $17.3 \mathrm{MPa}$ とそれぞれ設定した．水蒸気の温度及び圧力は実機 SGにおける伝熱管内部の条件であるが, こ れをよどみ点の状態として決定される臨界流状態を噴出口の境界条件として与えた．このとき，噴出口での水蒸 気速度は音速（約 $618 \mathrm{~m} / \mathrm{s}$ ） となる。噴出口を除く底面には non-slip 条件, その他の境界には圧力一定条件を適用 した.
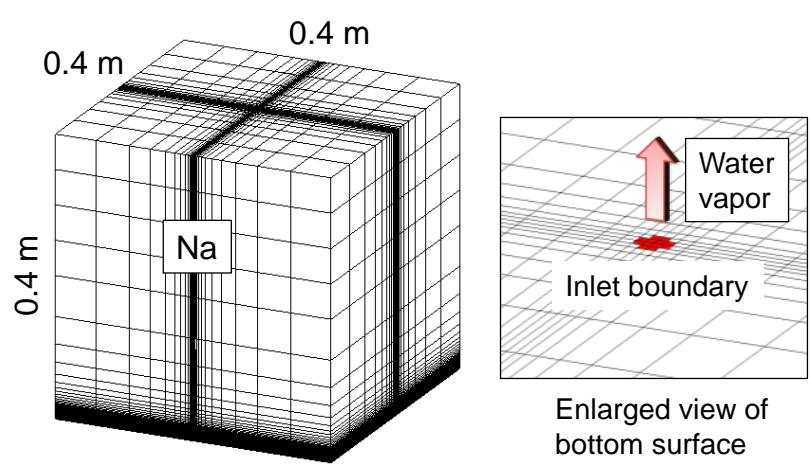

Fig.2 Computational domain

\section{$3 \cdot 2$ 解析結果及び考察}

図 3 に, 噴出開始後 $0.2 \sim 0.4$ 秒の間で時間平均を施した気相及び液滴の体積率，温度，速度（噴出口近傍の拡 大表示）の分布をそれぞれ示す．これらはいずれも噴出口中心と交わる鉛直断面内の分布を表している．気相及 び液滴の体積率分布より, 気相の存在する領域の内部で液滴が発生していることが分かる. 気相温度は, 化学反 応により最大で約 $1250^{\circ} \mathrm{C}$ に達している. 前述した温度・圧力条件のもとで実施された $\mathrm{Na}$ 中水蒸気噴出実験(6)で も同程度の最高温度が計測されていることから，本解析結果は妥当であることが分かる．気相速度は超音速まで 増大し, 最大で約 $1500 \mathrm{~m} / \mathrm{s}$ に達している. 前述した水蒸気の圧力及び温度の条件（よどみ点状態）から噴出口の 圧力 (臨界流状態) を理論的に計算すると $8.8 \mathrm{MPa}$ となり, これは背圧の $0.2 \mathrm{MPa}$ を大きく超えている. そのため, 気相が噴出した後に不足膨張が生じるが，これが超音速領域の形成された原因である。一方，液滴は最大百数十 $\mathrm{m} / \mathrm{s}$ 程度で気相に随伴する結果となった. 既往知見 ${ }^{(7)}$ から, この液滴速度はエロージョンの発生する条件に達して いると考えられる，以上に述べた通り，新たに構築した解析モデルは液滴のエントレインメント及び輸送現象を 解析できる機能を有していることが分かる. 


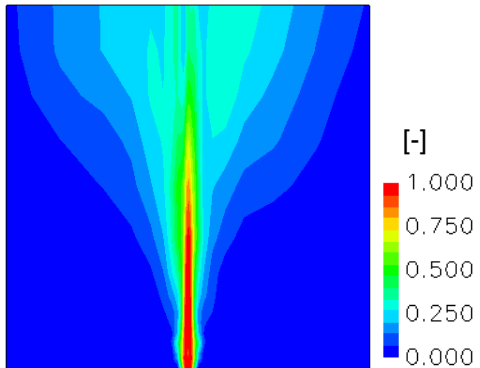

Void fraction

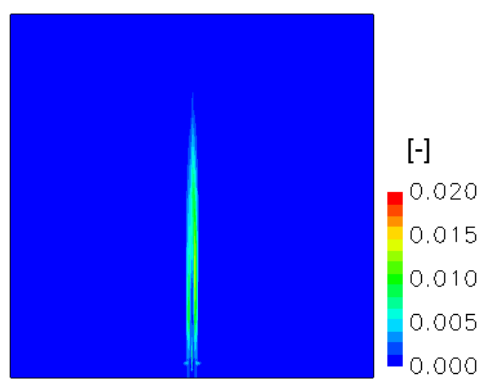

Volume fraction of droplet

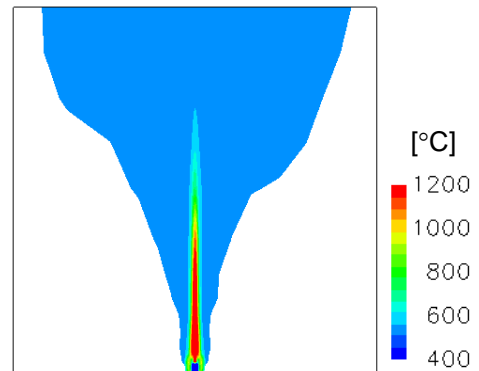

Gas-phase temperature

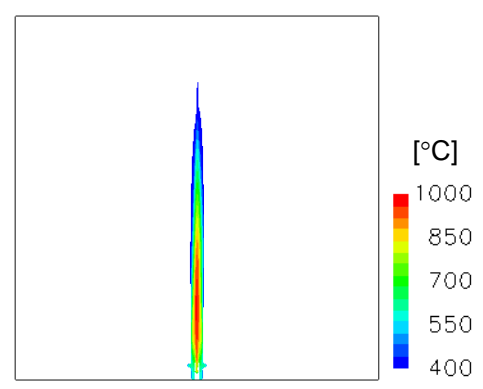

Droplet temperature
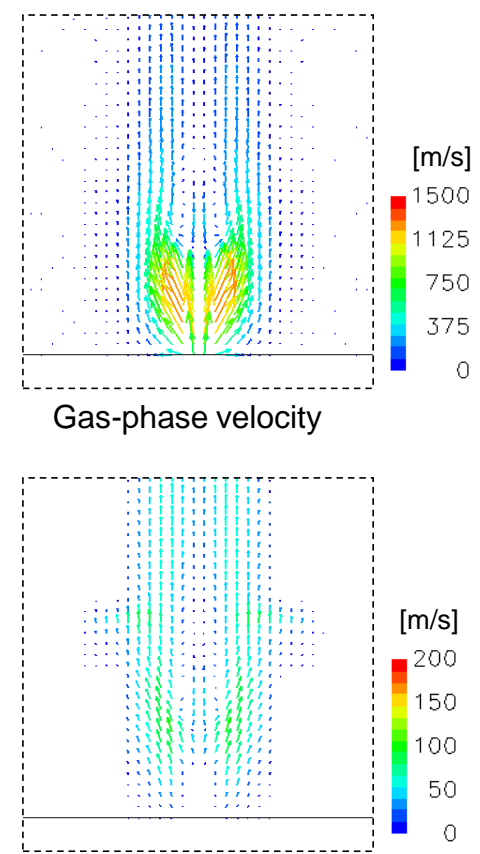

Droplet velocity

Fig.3 Numerical results

\section{4. 結 語}

実機条件での $\mathrm{Na}$ 中水蒸気噴出現象を解析し, 水蒸気の噴出挙動や化学反応による最大到達温度について妥当 な結果を得るとともに，新たに構築した液滴エントレインメント・輸送モデルが機能し， ウェステージ環境の一 つとして液滴挙動を評価できる見通しを得た．今後は，関連実験の解析から定量的な妥当性検証を実施する予定 である.

本報告は, エネルギー対策特別会計に基づく文部科学省からの受託事業として, 原子力機構が実施した平成 22 年度「蒸気発生器伝熱管破損伝播に係るマルチフィジックス評価システムの開発」の成果である.

\section{文献}

（1）内堀昭寛, 渡部晃, 大島宏之, “ナトリウム一水反応および圧縮性混相流数值解析コード SERAPHIM の高度化（化 学反応を伴う液体中気体噴流に対寸る再現性検証)”, 日本機械学会論文集 B 編, Vol. 77, No. 776 (2011), pp. 974-977.

(2) Ricou, F.P., and Spalding, D.B., "Measurements of Entrainment by Axisymmetrical Turbulent Jets", Journal of Fluid Mechanics, Vol. 11 (1961), pp. 21-32.

(3) Epstein, M., Fauske, H.K., Yoshioka, N., Tashimo, M., Sakaba, H., and Kotake, S., "Analytical Model for Peak Temperature within a Sodium-water Reaction Jet”, Journal of Nuclear Science and Technology, Vol. 43 (2006), pp. 43-54.

(4) Walsh, M.J., "Influence of Particle Drag Coefficient on Particle Motion in High-speed Flow with Typical Laser Velocimeter Applications", NASA TN D-8120 (1976), National Aeronautics and Space Administration, Washington, DC.

(5) Epstein, M., Fauske, H.K., and Yoshioka, N., "Establishment of Analytical Model for Peak Temperature within a Sodium-water Reaction Jet, (II) Mean Droplet Size in a Submerged Gas Jet", Journal of Nuclear Science and Technology. Vol. 42 (2005), pp. 961-969.

(6) 栗原成計, 下山一仁, 浜田広次, 大島宏之, “高速実用炉蒸気発生器における伝熱管破損事象に関する研究 (2)中 規模水リーク実験”, 日本原子力学会 2011 年春の年会, (2011), H12.

(7) William, K.C.W., Higashi, Y., Narabayashi, T., Tsuji, M., Ohshima, H., and Kurihara, A., "Study on Steam Generator Tube Wastage (9) Evaluation of LDI Test by Using High Speed Rotating Disc”, 日本原子力学会 2011 年秋の大会, (2012), P12. 